\title{
Paulo Freire e Gert Biesta: um diálogo FECUNDO SOBRE A EDUCAÇÃO PARA ALÉM DA FACILITAÇÃO DA APRENDIZAGEM
}

\author{
AleXANDRE ANSELMO GUILHERME \\ Ana LuCIa Souza de Freitas \\ Pontifícia Universidade Católica do Rio Grande do Sul (PUCRS), \\ Porto Alegre, Rio Grande do Sul, Brasil
}

\begin{abstract}
Resumo: A aproximação entre Paulo Freire e Gert Biesta foi realizada a partir de estudos bibliográficos, tendo como foco a compreensão de ambos acerca das relações entre risco e educação. Por que é importante compreender (e exercer) a educação como risco? Qual a função dos educadores que assumem a educação como risco? São os questionamentos que orientam o desenvolvimento do estudo realizado, o qual proporcionou a compreensão de que o conceito de learnification, traduzido como aprenderismo, e a concepção de educação como risco são relevantes proposições do pensamento de Gert Biesta que contribuem para a atualização e recriação do pensamento freireano diante dos desafios contemporâneos, como o de reinventar a linguagem da educação.
\end{abstract}

Palavras-Chave: Paulo Freire. Gert Biesta. Risco. Learnification. Aprenderismo.

INTRODUÇÃO

A proposição do diálogo entre o pensamento de Paulo Freire e o de Gert Biesta se insere no âmbito dos estudos que têm como objetivo problematizar a atualidade do pensamento freireano, em diálogo com outros/ as autores/as (FREITAS; GHIGGl; PEREIRA, 2014; LUFT; FALKEMBACH, 2013). $\mathrm{O}$ estudo realizado teve como foco a compreensão de ambos acerca das 
relações entre risco e educação, por ser este um dos aspectos que evidencia a proximidade do pensamento dos autores no que se refere à radicalidade de seu posicionamento acerca da educação como formação humana. Essa temática, o risco e a educação, são muito relevantes e atuais porque existe uma tendência crescente de mercantilização da educação em muitos países, e isso traz importantes consequências para a relação entre professor e estudante por exemplo, o aluno consumidor precisa estar sempre feliz ou contente, o que instiga o professor (e a escola) a procurarem diminuição do risco, do incerto, do surpreendente na educação. Entretanto, como Biesta e Freire demonstram: o risco faz parte do processo educativo. Ademais, estudos filosóficos como esse são importantes porque a filosofia nos ajuda a problematizar teorias, a questionar conhecimentos e atitudes, e a descobrir novas possibilidades. Como Smeyers, Smith e Standish (2010, p. 215, tradução nossa) comentam:

Wittgenstein escreve que "a filosofia simplesmente coloca tudo diante de nós, e nem explica nem deduz nada - já que tudo está aberto à vista, não há nada a explicar" (Philosophical Investigations 1.126)... Na verdade não há nada a explicar, mas o problema está resolvido, O"nó da mãe" é desembaraçado, nas palavras de Suissa (2005), através da descoberta de uma linguagem rica e responsiva que faz justiça aos fenômenos.

Assim sendo, e com base nos estudos realizados, argumenta-se que o pensamento de Gert Biesta, um filósofo da educação contemporâneo holandês, radicado no Reino Unido, está em consonância com a noção de risco presente na obra de Paulo Freire. A obra de Biesta apresenta novos conceitos que atualizam a reflexão educacional de Freire, problematizando a linguagem dominante e fundamentando uma compreensão ampliada acerca da educação como risco. Compreende-se que a complementaridade do pensamento de Freire e de Biesta contribui para propor a discussão sobre as finalidades da educação diante dos desafios contemporâneos, entre outros, o de reinventar a linguagem da educação para fazer jus aos desafios correntes, como o uso de tecnologias e processo de mercantilização na educação.

Ambos abordam a natureza difícil da tarefa educativa e problematizam as situações em que a aprendizagem é descrita como fácil e agradável e a função do/a educador/a reduzida a um facilitador, cuja responsabilidade principal seria quase exclusivamente a de criar oportunidades e um clima favorável para que os estudantes aprendam. Nesse sentido, se faz fecundo propor o diálogo entre o pensamento dos referidos autores para compreender a complexidade e a dificuldade das relações de ensinar e de aprender, bem como a urgência de resgatar a reflexão sobre a função de ensinar. 
Paulo Freire representa um marco na história da educação brasileira e de outros países. Ao criar a metáfora da educação bancária para nomear as práticas educativas que reduzem os educandos a meros depositários de informação, tornou-se referência por sua proposição acerca de uma educação problematizadora e libertadora, cuja teorização veio a constituir-se como uma das tendências pedagógicas no campo da pedagogia progressista (FREITAS, 2014). Seu pensamento tem orientado práticas educativas que, em diferentes contextos de atuação, compreendem sua natureza política, desafiando a constituição de possibilidades. Segundo Freire,

(...) sabemos todos que a educação não é a chave das transformações do mundo, mas sabemos também que as mudanças do mundo são um quefazer educativo em si mesmas. Sabemos que a educação não pode tudo, mas pode alguma coisa. Sua força reside exatamente na sua fraqueza. Cabe a nós por sua força a serviço dos nossos sonhos (FREIRE, 1991, p. 126).

Sendo assim, o pensamento freireano ${ }^{1}$ mobiliza a autoria de educadores e educadoras à constituição de práticas educativas transformadoras de indivíduos e sociedades, práticas libertadoras que visam resolver a dicotomia opressor-oprimido. Isso requer desses educadores e educadoras a disponibilidade ao risco, que se manifesta e decorre de nossa capacidade de sonhar e de transgredir limites impostos (FREIRE, 1983).

Gert Biesta é professor de teoria e política educacional no Departamento de Educação da Brunel University London e editor da revista Studies in Philosophy and Education, reconhecido internacionalmente como referência da pedagogia crítica. Sua única obra traduzida para o português - Para além da aprendizagem: educação democrática para um futuro humano (2013a) - contou com a presença do autor para seu lançamento no Brasil², mas apesar da relevância desta publicação, o autor ainda é pouco conhecido entre educadores e educadoras brasileiros/as ${ }^{3}$.

Uma das ideias organizadoras do pensamento de Gert Biesta é a sua compreensão de que, nos últimos anos, a linguagem da educação vem sendo substituída pela linguagem da aprendizagem. Segundo o autor, algo se perdeu nesta mudança de foco, visto que "ensinar foi redefinido como apoiar ou facilitar a aprendizagem" (BIESTA, 2013a, p. 32) - quer dizer, houve uma mudança paradigmática, do paradigma da educação para o paradigma da aprendizagem. Isso leva Biesta a criar o termo learnification, que traduzimos como aprenderismo, para expressar sua compreensão acerca da exacerbação da linguagem da aprendizagem no discurso educacional contemporâneo (BIESTA, 2005; 2013b). Biesta julga esse aprenderismo como algo problemático e com sérias consequências para a educação, assunto que 
discutimos em detalhe mais abaixo. Entre outras, esta problematização é uma importante contribuição do autor para a atualidade da pedagogia crítica, cuja proximidade com o pensamento de Paulo Freire se faz muito fecunda e de forma que, como sugerimos, atualiza e reconcebe o pensamento de Freire.

A aproximação entre o pensamento de Gert Biesta e de Paulo Freire foi realizada a partir de estudos bibliográficos. O estudo do pensamento de Gert Biesta tomou como referência a leitura das obras Para além da aprendizagem: educação democrática para um futuro humano (BIESTA, 2013a) e The beautiful risk of education (BIESTA, 2013b), além de artigos em periódicos (BIESTA, $2005,2012)$. A análise do pensamento de Paulo Freire tomou como ponto de partida a leitura do verbete risco, integrante do Dicionário Paulo Freire (STRECK; REDIN; ZITKOSKI, 2010) e, a seguir, as obras nele indicadas como referência do tema: Educação e mudança (FREIRE, 1979); Pedagogia da Autonomia (FREIRE, 1996); Pedagogia da Indignação (FREIRE, 2000). Adicionalmente, as obras Medo e ousadia: o cotidiano do professor (FREIRE, SHOER, 1986) e Pedagogia da Esperança (FREIRE, 1992) também serviram de referência para este estudo, visto que o foco no risco, inicialmente estabelecido, ampliou-se pela complementaridade de dois focos emergentes na análise: o medo e a ousadia.

Com base nos estudos realizados, argumenta-se acerca da complementaridade entre o pensamento de Paulo Freire e o de Gert Biesta para a compreensão das relações entre educação e risco, considerando ser esta uma importante contribuição para promover a atualização da reflexão sobre os sentidos e as finalidades da educação, diante dos desafios contemporâneos, entre outros e como já dito, a necessidade de reinventar a linguagem da educação. Mas por que é importante compreender (e exercer) a educação como risco? Em que consiste a dificuldade da educação? Qual a função dos educadores que assumem a educação como risco? São os questionamentos que orientam o desenvolvimento da escrita para estabelecer o diálogo entre o pensamento dos autores. Inicialmente, o texto apresenta o pensamento de cada um dos autores, sem a intenção de sintetizá-los, mas, de instigar a curiosidade para o seu aprofundamento. A seguir, argumenta a complementaridade de suas contribuições para refletir a educação, enfatizando a necessidade de que se problematize a linguagem educacional dominante para recuperar a discussão acerca dos sentidos e finalidades da educação, bem como da função de ensinar.

O PENSAMENTO FREIREANO SOBRE O RISCO NA EDUCAÇÃO

A noção de risco é um elemento presente no pensamento freireano para expressar sua concepção de uma educação problematizadora e 
libertadora. Risco é um dos verbetes integrantes do Dicionário Paulo Freire (STRECK; REDIN; ZITKOSKI, 2010), cuja publicação destina-se a dar visibilidade aos conceitos fundantes do pensamento freireano, de modo a orientar o aprofundamento de estudos. Os autores do referido verbete afirmam que "Para Paulo Freire, a possibilidade do risco é algo inerente ao existir. É impossível viver sem correr risco, sem estar aberto à incerteza, ou seja, ao encontro com o inusitado ou novo" (FISCHER; LOUSADA, 2010, p. 363). Além de ser um elemento presente na experiência humana, consiste num fator intrínseco ao ato de aprender, que exige acolhida ao risco. Por isso, afirmam que, no pensamento freireano, a educação não nega o risco, mas, ao contrário, estimula os educandos a assumi-lo e a aprender a lidar e agir competentemente diante de sua inevitabilidade.

O risco é tematizado em várias obras de Paulo Freire. Na obra Pedagogia da Indignação, Freire reitera sua compreensão de que "não haveria cultura nem história sem risco, assumido ou não; quer dizer, risco de que o sujeito que o corre se acha mais ou menos consciente" (FREIRE, 2000, p. 30). Assim, o autor nos desafia à tomada de consciência da educação como risco. Na Pedagogia da Autonomia, ao apresentar o tema Ensinar exige risco, aceitação do novo e rejeição a qualquer forma de discriminação (FREIRE, 1996, p. 39), o autor argumenta que a disponibilidade ao risco e a aceitação do novo são condições para um dos saberes necessários à prática educativa, o pensar certo. De modo enfático, Freire conclui que "quem pensa certo está cansado de saber que as palavras a que falta a corporeidade do exemplo pouco ou quase nada valem. Pensar certo é fazer certo" (FREIRE, 1996, p. 38). Pensar certo é, portanto, arriscar-se.

Nas obras Medo e ousadia: o cotidiano do professor e Pedagogia da Esperança, Freire convida educadores e educadoras à reflexão sobre sua prática, considerando, entre outras questões, o risco da incoerência e o risco de influenciar os alunos. Ao desenvolver sua reflexão a este respeito, destaca a diretividade como um elemento constituinte da função do educador, afirmando que"Qualquer que seja a qualidade da prática educativa, autoritária ou democrática, ela é sempre diretiva" (FREIRE, 1992, p. 79). Ou seja, o que torna uma prática educativa autoritária não é a presença ou ausência de diretividade. A diretividade do/a educador/a é o que caracteriza a consciência sobre a natureza política de sua prática. O que não significa, contudo, uma ação impositiva nem hierárquica. Este ponto é importante porque muitos teóricos tendem a entender que Freire defendia uma educação não-diretiva por causa de várias passagens na Pedagogia do Oprimido, na qual, Freire comenta que "ninguém educa ninguém, ninguém educa a si mesmo, os 
homens se educam entre si, mediatizados pelo mundo" (FREIRE, 1987, p. 39; LEACH 1982; SCHUGURENSKY, 1998). Freire foi enfático quando perguntado sobre isso:

Realmente eu nunca disse que o educador é igual ao educando. Ao contrário, sempre disse que a afirmação dessa igualdade é demagógica e falsa. O educador é diferente do educando. Mas essa diferença, na perspectiva da revolução, não pode ser antagônica. A diferença se torna antagônica quando a autoridade do educador, diferente da liberdade do educando, se transforma em autoritarismo. É essa exigência que eu faço ao educador revolucionário. Para mim, é absolutamente contraditório que o educador, em nome da revolução, se apodere do método e autoritariamente comande o educando, em nome dessa diferença que há. Essa é a minha posição, e por isso me surpreendo quando dizem que eu defendo uma posição não-diretiva. Como se eu pudesse negar o fato inconteste de que a natureza do processo educativo sempre é diretiva, não importando se a educação é feita pela burguesia ou pela classe trabalhadora (FREIRE et al., 1988, p. 60).

Importa ainda referir que, no pensamento freireano, o tema do risco também suscita a reflexão sobre o medo. Na obra Educação e mudança, ao apresentar sua reflexão sobre o compromisso do profissional com a sociedade, Paulo Freire faz referência ao"medo de correr o risco da aventura de criar"(FREIRE, 1979 , p. 25), afirmando que correr o risco é o que caracteriza a coragem do compromisso. Assim, assumir o risco inerente ao ato de aprender (e de ensinar) diz respeito ao reconhecimento de que não há educação sem envolvimento da subjetividade dos sujeitos, visto que uma educação problematizadora e libertadora é produto-produtora da criticidade, da curiosidade e da criatividade nos processos de ensinar e de aprender (FREITAS, 2001).

Em síntese, para Paulo Freire, a tensão entre medo e ousadia condiciona homens e mulheres na experiência de arriscar-se. Assumir o medo é uma atitude de criticidade necessária para exercer a ousadia de assumir riscos, visto que a prática educativa transformadora requer, entre outras, a compreensão de que "[...] mudar é difícil, mas é possível. Devemos insistir sobre a possibilidade de mudar, apesar das dificuldades" (FREIRE, 1995, p. 48). Philippe Meirieu, o grande teórico da educação frances, é outro autor que comenta a importância do medo e do risco para a educação, criticando tendências contemporâneas; ele aponta que:

Para superar nosso medo da aprendizagem, devemos, na verdade, saber com a convicção interior que nos dá força para superar todas as inibições - que vivemos o momento e num "espaço sem ameaças." Devemos estar convencidos de que temos o direito de apalpar, de cometer erros e até mesmo 
falhar. Então ninguém vai rir de você. Estigmatizar você, trancá-lo para sempre em uma tentativa fracassada. Que ninguém - nem um de seus amigos ou seus pais ou seus professores - o etiquetará e absorver você para sempre ao que é apenas um passo em um longo processo de aprendizagem, nunca realmente terminado ... $\mathrm{E}$, em seguida, também requer que o professor esteja lá para permitir que o aluno "assuma riscos" sem "pôr em perigo" "assumir riscos", porque o risco é inerente a qualquer atividade de aprendizagem, por definição imprevisível, mas sem comprometer, "sem por em perigo" de uma forma ou de outra, sua integridade física ou psicológica. Construir em torno da criança "um espaço sem ameaças", permite que ele/a possa domar o medo que domina toda vez que ele encontra um futuro potencial, mas imprevisível (MEIRIEU, s/d, p. 6. tradução nossa).

Ou seja, a disponibilidade ao risco se inscreve numa concepção não determinista da história; requer compreender, nas palavras Freire, a história como possibilidade e a prática educativa como parte do compromisso com a transformação social. Por isso, a noção de risco no pensamento freireano está associada à sua compreensão de educação como sonho possível. Esta é uma marca de sua dimensão utópica, fundada numa concepção de que pode se concretizar, no sentido que nos aproximamos paulatinamente e cada vez mais dela. Isso se faz indispensável para a ousadia de, cotidianamente, enfrentar os riscos que obstaculizam essa utopia possível.

Segundo o autor, trata-se de "uma prática que vive a unidade dialética, dinâmica, entre a denúncia e o anúncio, entre a denúncia de uma sociedade injusta e expoliadora e o anúncio do sonho possível de uma sociedade que pelo menos seja menos expoliadora" (FREIRE, 1983, p. 100). Assim, convida educadores e educadoras a exercer a sua capacidade de sonhar coletivamente, enfatizando a compreensão do caráter revolucionário do ato de sonhar:

Eu agora diria a nós, como educadores e educadoras: ai daqueles e daquelas, entre nós, que pararem com a sua capacidade de sonhar, de inventar a sua coragem de denunciar e de anunciar. Ai daqueles e daquelas que, em lugar de visitar de vez em quando o amanhã, o futuro, pelo profundo engajamento com o hoje, com o aqui e o agora, ai daqueles que em lugar desta viagem constante ao amanhã, se atrelem a um passado de exploração e de rotina (FREIRE, 1983, p. 101).

Todavia, esta é uma atitude transgressora, que não se realiza sem a disposição ao risco. Enfrentar os riscos de viver a educação como forma de luta por sonhos possíveis é um grande legado de Paulo Freire que precisa ser preservado, tanto quanto atualizado e recriado diante dos desafios contemporâneos. Para tanto, o diálogo com outros autores se faz fecundo. Assim, trazendo Biesta, que influenciado por Freire argumenta que essa 
visão, viver o risco, tem uma consequência importante para a educação e para um melhor entendimento da obra de Freire. Bingham e Biesta (2010, p. 76, tradução nossa, grifo nosso) argumentam que:

Deve ficar claro para quem leu este resumo da educação bancária e seu antídoto, o método de 'problem-posing', ou para quem estuda o trabalho de Freire, que a aplicação do método de apresentação de problemas é um meio de levar os alunos de um estado psicológico para outro. É através do método de 'problem-posing' que uma equação psíquica desequilibrada de professor e aluno vai mudar em um estado de equilíbrio psíquico entre professor e aluno.

\section{O PENSAMENTO DE GERT BiESTA ACERCA DA EDUCAÇÃo COMO RISCO}

Gert Biesta nos convida a problematizar a linguagem educacional dominante em função de sua centralidade na aprendizagem. O problema da nova linguagem da educação, segundo o autor, diz respeito ao modo como, nas últimas décadas, a ênfase atribuída à aprendizagem, com foco nos "sujeitos aprendentes", nos "ambientes de aprendizagem" e/ou nos "objetos de aprendizagem" redefiniu a função do professor como um facilitador, reduzindo a função educacional de ensinar (BIESTA, 2012).

O autor apresenta duas objeções contra a linha de pensamento que tornou possível a nova linguagem da aprendizagem; a primeira é que esta linguagem facilita uma compreensão das relações educacionais como relações econômicas. Conceber o estudante como um consumidor e a educação como mercadoria distorce a função do educador que, visto como um provedor, cujo objetivo é a satisfação dos interesses do estudante, deixa de exercer sua função de ensinar. A segunda objeção é a de que conceber as relações educacionais como relações econômicas torna mais difícil propor questões acerca dos objetivos e conteúdos da educação que não sejam as propostas pelo mercado educacional (BIESTA, 2013a), ou seja, desproblematizar os sentidos e as finalidades da educação e supervalorizar sua dimensão técnica e metodológica.

Partindo desta compreensão, considera que um dos desafios da atualidade é o de reinventar uma linguagem para a educação, capaz de responder às novas questões com as quais estamos nos defrontando. Mas por que a linguagem importa à educação? É o questionamento a que ele se posiciona, argumentando que "[...] a linguagem - ou as linguagens - existente para a educação influencia em grande medida o que pode ser dito e feito, e também o que não pode ser dito e feito" (BIESTA, 2013a, p. 30). Assim, quando 
o paradigma da aprendizagem, e sua linguagem, se estabelece e se torna hegemônico no contexto educacional, ele traz consigo certa visão do mundo que se contrapõe ao paradigma da educação, e a sua própria linguagem. Dessa maneira, fica praticamente impossível dizer que o professor/a é alguém que tem um especialismo e um conhecimento a ser passado para uma nova geração, que o estudante tem que enfrentar desafios e que o processo de educação envolve frustrações, medos e riscos. Ao invés disso, assume-se o discurso do professor facilitador da aprendizagem, do estudante que precisa estar sempre feliz e satisfeito, e que o processo de aprendizagem tem que ser baseado numa idéia de conforto e cuidado. Isso torna impossível, o já referido constante movimento de desiquilibrio e equilibrio psiquíco entre professor e estudante (BINGHAM; BIESTA 2010, p. 76). Um movimento apreciado tanto por Freire como por Biesta.

Assim, ao criar o conceito de learnification, o autor expressa sua preocupação e contrariedade acerca da exacerbação da linguagem da aprendizagem no discurso educacional contemporâneo (BIESTA, 2005; 2013b) e nos desafia à sua reinvenção. Em consonância com Biesta, propomos, como já foi dito anteriormente, o conceito de aprenderismo para traduzir a indignação expressa no conceito de learnification, na expectativa de que o aprenderismo possa vir a ser assumido como uma referência para problematizar a linguagem educacional dominante, bem como para expressar o compromisso com sua reinvenção.

A reinvenção da linguagem educacional é um dos caminhos para promover a discussão acerca dos sentidos e finalidades da educação, bem como da função de ensinar. Biesta (2014, p. 88) comenta que: "'Learnification' se refere a uma construção relativamente recente na qual a linguagem da educação tem sido substituída por uma linguagem da aprendizagem (BIESTA, 2013a). Como resultado, a ênfase nessa discussão deslocou-se das questões sobre o conteúdo e o propósito da educação para questões sobre processos, como, por exemplo, na ideia agora onipresente de 'aprender a aprender'".

No âmbito desta reflexão, merece destaque a distinção feita por Biesta entre "learning from" e "being taught by" (BIESTA, 2013b), ou seja, entre aprender com e ser ensinado por (tradução nossa). $\mathrm{O}$ autor questiona a concepção de educador como facilitador e enfatiza a necessidade de que educadores e educadoras recuperem sua função de ensinar (BIESTA, 2012). Quer dizer, há algo fundamentalmente diferente em entre'aprender algo com alguém'e ser'ensinado algo por alguém'. Quando dizemos'aprender algo com alguém'a função do outro, do/a professor/a, fica esvaziada e sua importância diminuída; e dependendo de entendimentos mais radicais, a função do 
professor passa a ser até desnecessária. Mas quando dizemos 'ser ensinado por' entendemos que o professor/a tem de fato uma função importante, fundamental, no processo de educação. Vale notar que Biesta não defende a volta do professor autoritário e da educação bancária, tão criticada por Freire; muito pelo contrário, o que Biesta de fato defende é o reconhecimento que o/a professor/a tem papel fundamental na educação crítica. Nesse sentido, Biesta é crítico da educação centrada no estudante;"por exemplo, Steiner ou Waldorf em que tudo que está no currículo, tanto no acadêmico quanto no profissional, é, em última análise, visto como uma oportunidade para que as crianças encontrem o mundo e, por meio disso, encontrem a si mesmas. Isso não significa que adquirir de forma correta se torne irrelevante, mas significa que nunca funciona como um fim em si mesmo" (BIESTA 2014, p. 89). Isso está em perfeita consonância com o pensamento freireano. Por isso, Biesta prefere os termos professor e educação ao invés de facilitador e aprendizagem e isso permanece uma constante em seu trabalho.

Assim, ao conceber a educação como risco, Biesta se posiciona radicalmente contra a compreensão da relação educacional como uma relação econômica, ou seja, uma relação entre provedor e consumidor, na qual o risco é indesejável. Inversamente, a relação educacional inexiste sem risco, considerando que:

[...] mesmo que alguém se engaje em formas muito bem organizadas de aprendizagem, há sempre um risco. Não só existe o risco de que você não aprenda o que queria aprender (e nesse caso você poderia processar o provedor). Existe também o risco de que você aprenda coisas que nem teria imaginado que aprenderia, ou que você nem teria imaginado que desejaria aprender. E existe o risco de que você aprenda algo que preferiria não aprender - algo sobre si mesmo, por exemplo. Engajar-se em aprender sempre acarreta o risco de que a aprendizagem possa ter um impacto sobre você, de que a aprendizagem possa mudá-lo. Isso significa que a educação só começa quando o aprendente está disposto a correr um risco (BIESTA, 2013a, p. 44-45).

Para Biesta, quando buscamos tornar a educação numa experiência sem riscos, entramos num cenário no qual não podemos mais fazer indagações, não podemos mais ser questionados, não podemos mais ser tocados, e as questões nunca se voltam ou se dirigem a nós. Por outro lado, a concepção de educação como risco admite a dificuldade que existe na relação educacional, precisamente porque "é sempre uma intervenção na vida de alguém; uma intervenção motivada pela ideia de que se tornará essa vida, de certo modo, melhor; mais completa, mais harmoniosa, mais perfeita - e talvez até mais humana" (BIESTA, 2013a, p. 16). 
Enfim, compreender (e exercer) a educação como risco é importante para recuperar os sentidos e as finalidades da educação, para além de facilitar a aprendizagem. Isso representa uma reformulação do paradigma da educação e requer compreender a complexidade e as dificuldades inerentes aos processos de formação humana. Nesta perspectiva, merece destaque a proposição de Gert Biesta ao apresentar os três conceitos que expressam sua compreensão acerca do que constitui a relação educacional. Segundo ele, assumir a educação como risco requer compreender a relação educacional como uma relação de confiança (sem fundamento), de violência (transcedental) e de responsabilidade (sem conhecimento). Esses conceitos podem causar certo estranhamento, entretanto têm de ser entendidos no contexto de pedagogia crítica e de uma tão necessária reformulação da linguagem educacional.

Sendo assim, a confiança está relacionada ao risco, inerente ao ato de aprender, que diz respeito à qualidade de uma relação em que não é possível exercer o absoluto controle sobre o processo nem sobre seus resultados, ou seja, uma relação que não pode ser substituída nem expressa por cálculos. Sendo assim, a confiança se faz necessária para assumir riscos. Todavia, sendo a confiança também de natureza incalculável, não é possível que a confiança em alguém seja fundamentada, no sentido de ser uma certeza absoluta - assim, como já foi dito, a confiança sempre envolve um risco. Daí a proposição do autor em nomear como um elemento constituinte da relação educacional a confiança sem fundamento.

A violência diz respeito ao reconhecimento de que as relações educacionais "não são necessariamente fáceis ou agradáveis. Ao propor as questões difíceis que permitem aos estudantes vir ao mundo, desafiamos e possivelmente perturbamos quem nossos estudantes são e onde estão" (BIESTA, 2013a, p. 50). O autor concebe a aprendizagem como resposta, considerando ser esta uma concepção mais significativa do que a aprendizagem como aquisição. Educadores/as que concebem a aprendizagem como resposta, desafiam os estudantes a posicionar-se diante de questões difíceis; sendo assim, indivíduos não fogem dos grandes problemas enfrentados pela humanidade, pelo mundo, procurando entendê-los e resolvê-los. Obviamente não significa sugerir que a educação seja violenta no sentido estrito da palavra, mas para chamar atenção de que "[...] como educadores, estamos sempre interferindo nas vidas de nossos estudantes, $\mathrm{e}$ que essa interferência pode ter um impacto profundo, transformador e até perturbador sobre nossos estudantes" (BIESTA, 2013a. p. 50). Daí a proposição de uma violência transcedental, ou seja, que torna possível ao sujeito sua 
vinda ao mundo como um ser único, outro elemento constituinte da relação educacional.

A responsabilidade referida por Biesta diz respeito à compreensão de que, se o/a professor/a tem como finalidade que os estudantes aprendam a "responder", de modo a que se tornem seres únicos e singulares, isto não é uma tarefa fácil. Implica"a responsabilidade por alguma coisa (ou melhor, por alguém) que não conhecemos e não podemos conhecer" (BIESTA, 2013a, p. 51), ou seja, não podemos saber tudo sobre os estudantes antes de assumir a responsabilidade por eles, nem podemos saber o que vai acontecer no futuro. Daí a concepção de responsabilidade sem conhecimento, sendo este um terceiro elemento constituinte da relação educacional.

Enfim, a confiança sem fundamento, a violência transcedental e a responsabilidade sem conhecimento, como três conceitos entrelaçados, expressam a compreensão de Gert Biesta acerca da complexidade das relações educacionais, na perspectiva da educação como risco. Ao nomeálos, o autor chama atenção para as dificuldades da função de ensinar e contribui para reinventar a linguagem educacional dominante, apresentando novos e instigantes elementos que se compreenda a educação como risco e desafiando educadores e educadoras a se assumirem protagonistas neste processo.

\section{CONSIDERAÇÕES PARA PENSAR A EDUCAÇÃO PARA ALÉM DE FACILITAR A APREN- DIZAGEM}

Um dos questionamentos que têm sido recorrentes, no âmbito educacional, de modo explícito ou implícito, é: "como mobilizar o aluno para o aprender?" (GRILLO et al., 2008). Historicamente, a busca de respostas a esta e outras questões a ela associadas apresentou diferentes ênfases e abordagens (MIZUKAMI, 2012), tendo em comum a intencionalidade de superar práticas educativas tradicionalmente centradas no professor, denominada por Freire de educação bancária (FREIRE, 1987).

No âmbito desta reflexão, o lema "aprender a aprender", expressão do ideário pedagógico escolanovista, também conhecido como movimento "escola ativa", representou significativo avanço quanto ao questionamento das práticas tradicionais no que se refere à passividade do aluno e à descontextualização do ensino, entre outros aspectos, chamando atenção para a valorização da experiência e para a criação de ambientes propícios ao desenvolvimento da autonomia dos estudantes. Todavia, a concepção do aluno como centralidade do processo relativizou o valor dos conteúdos em função do método, assim como a própria função do educador (DUARTE, 2000). 
A este respeito, Duarte (2000) identifica quatro posicionamentos valorativos do "aprender a aprender" que marcaram fortemente o discurso pedagógico:

1. As aprendizagens que o indivíduo realiza por si mesmo são mais desejáveis do que aquilo que aprende através de outras pessoas;

2. É mais importante desenvolver um método de construção de conhecimentos do que aprender os conhecimentos já produzidos socialmente;

3. A atividade do aluno deve ser dirigida por seus interesses e necessidades;

4. A educação deve preparar os indivíduos para acompanhar a sociedade em processo acelerado de mudança, cujas transformações tornam o conhecimento cada vez mais provisório.

$\mathrm{Na}$ atualidade desta reflexão, importa considerar que a presença das tecnologias tem cumprido importante papel em reforçar parte deste ideário pedagógico, o qual contribui para difundir um senso comum que relativiza a função do educador. Sendo assim, novos desafios se apresentam diante do cenário contemporâneo, em que as Tecnologias de Informação e Comunicação (TICS) anunciam práticas inovadoras que muitas vezes parecem comprometer a função e papel do professor (MORAES et al., 2015; 2013; FREITAS; GHIGGI; PEREIRA, 2014). Nesse sentido, vale mencionar aqui Bingham e Biesta (2010) que comentam em seu livro sobre Jacques Rancière, no qual o comparam com Freire. Os autores analisam a obra The lgnorant Schoolmaster (RANCIÈRE, 1991) que relata a experiência de Joseph Jacotot em Bruxellas no século XIX. Bingham e Biesta (2010, p. 1-2, tradução nossa) dizem:

Joseph Jacotot encontrou-se inesperadamente, na década de 1820, ensinando estudantes flamengos cuja língua ele não conhecia e que não conheciam a sua, usando um texto fortuito, uma edição bilingue... Dizia-se que ele ficava espantado com o modo como esses alunos, aos quais não transmitira qualquer conhecimento, tinham, seguindo seu comando, aprendido francês expressando-se muito bem, como lhes havia educado sem Ihes ensinar nada. A partir disso, concluiu que o ato do professor que obriga outra inteligência a exercer-se era independente da posse do conhecimento... ${ }^{4}$.

Entretanto, essa é uma visão reducionista do que realmente ocorre, é algo que tem sido usado por defensores do conceito de professor-facilitador. Os autores continuam: 
Um professor ignorante não é uma pessoa ignorante que gosta de se fazer de professor. É um professor que ensina - ou seja, que é para outro um meio de conhecimento - sem transmitir qualquer conhecimento. É, portanto, um professor que estabelece uma dissociação entre o domínio do professor e seu conhecimento, que nos mostra que a chamada"transmissão do conhecimento" consiste, de fato, em duas relações interligadas que são importantes para se dissociar: uma relação de vontade com vontade e uma relação de inteligência com inteligência (2010, p. 1-2, tradução nossa) $)^{5}$.

Assim, o ato de ensinar e aprender estão intrinsecamente interligados, a vontade de ensinar e a vontade de aprender, bem como uma inteligência criativa e crítica à outra. A reflexão filosófica traz a luz essas duas relações; sem tal reflexão temos apenas visão opaca do processo de educação. Tanto professor como estudante tem um papel a exercer no processo educativo, e apenas assim, a educação se torna eficaz e formadora. Desse modo, fica claro que a função de ensinar é uma questão que merece ser aprofundada para que, como propõe Biesta, o professor possa recuperar o direito de ensinar e a escola, mais do que um lugar de aprender, seja reconhecida como um lugar de ensinar, que se diferencia de outros espaços (BIESTA, 2012). Nesse sentido, o pensamento freireano continua sendo importante referência para tematizar a diretividade da função do educador e a não neutralidade da educação.

Sendo assim, mesmo correndo o risco de uma interpretação conservadora, o que seria algo errôneo tanto no caso de Biesta quanto de Freire, salientamos que será preciso avançar a discussão sobre a função de ensinar, bem como a importância da escola como um espaço formal de educação, desde uma perspectiva complexa, capaz de perceber o que precisa ser transformado sem desconsiderar o que precisa ser mantido. Paradoxalmente, posicionar-se sobre o que preservar, do ponto de vista da finalidade da educação e da função docente, é uma referência para expressar - e disputar - a direção das mudanças a serem construídas. Esta é uma discussão relevante, expressar uma perspectiva crítica da educação no cenário atual, na qual o diálogo entre o pensamento de Paulo Freire e Gert Biesta se faz fecundo ao promover a reflexão sobre a educação, para além de facilitar a aprendizagem. 


\section{PAULO FREIRE AND GERT BIESTA: A FECUND DIALOGUE ON EDUCATION BEYOND THE FACILITATION OF LEARNING}

ABSTRACT: Paulo Freire and Gert Biesta were brought together by bibliographic research focusing on these authors understanding about the relationship between risk and education. Why is it important to understand (and exercise) education as a risk? What is the role of educators who understand education as risk? These are the questions that guide this study, and which provides the understanding that the concept of learnification, translated as aprenderismo, and the concept of education as a risk are important proposals in the thought of Gert Biesta that updating and reconstruct some of Freire's conceptions in the light of contemporary challenges, such as the need to reinvent the language of education.

KEYwORDs: Paulo Freire. Gert Biesta. Risco. Learnification. Aprenderismo.

PAULO FREIRE Y GERT BIESTA: UN DIÁLOGO FECUNDO SOBRE LA EDUCACIÓN MÁS ALLÁ DE LA FACILITACIÓN DEL APRENDIZAJE

RESUMEN: La aproximación entre Paulo Freire y Gert Biesta aconteció a partir de estudios bibliográficos, que tenían como eje central la comprensión de esos autores sobre las relaciones entre riesgo y educación. ¿Por qué es importante entender (y ejercer) la educación como un riesgo? ¿Cuál es el rol de los educadores que entienden la educación como un riesgo? Esas son las preguntas que guían este estudio y, que permiten entender que el concepto de learnification, traducido como aprenderismo, y el concepto de educación como riesgo son propuestas importantes en el pensamiento de Gert Biesta y contribuyen para actualizar y recrear el pensamiento freireano, ante los desafíos contemporáneos, como el de reinventar el lenguaje de la educación.

Palabras-clave: Paulo Freire. Gert Biesta. Riesgo. Learnification. Aprenderismo.

\section{NOTAS}

1) Diferente do que indicam as normas ortográficas, a grafia empregada é a sugerida por Ana Maria Freire, mantendo inalterado o nome do autor.

2) O lançamento foi organizado pelo professor Walter Kohan, no dia 3 de junho de 2013, na Livraria da República da UERJ, durante a realização do VII Seminário Internacional As Redes Educativas e as tecnologias: transformações e subversões na atualidade, no Rio de Janeiro. A obra integra a Coleção Educação: Experiência e Sentido, organizada pelos educadores Walter Kohan e Jorge Larossa. 
3) Sobre Gert Biesta, em português, encontramos poucas resenhas de sua obra Para além da aprendizagem e no formato de artigo, uma publicação do Programa de Pós-Graduação em Educação da PUC Campinas (MENDONÇA; TORTELLA; SILVA, 2013).

4) Língua original: inglês.

5) Língua original: inglês.

\section{REFERÊNCIAS}

BIESTA, G. Against learning. Reclaiming a language for education in an age of learning. Nordisk Pedagogik, Oslo, v. 25, p. 54-66, 2005.

. Giving Teaching Back to Education: Responding to the Disappearance of the Teacher. Phenomenology \& Practice, v. 6, n. 2, p. 35-49, 2012.

. Para além da aprendizagem: educação democrática para um futuro humano. Tradução Rosaura Eichenberg. Belo Horizonte: Autêntica Editora, 2013a. (Coleção Educação: Experiência e Sentido).

. The beautiful risk of education. United States: Paradigman Publishers, $2013 \mathrm{~b}$.

. Pragmatismo, conhecimento e currículo: para além do objetivismo e do relativism. Revista Educação, PUC-Campinas, v. 19, n. 2, p. 87-98, 2014.

BINGHAM, C.; BIESTA, G. Jacques Rancière: Education, Truth, Emancipation. London; New York: Continuum, 2010.

DUARTE, N. Vigotski e o "aprender a aprender": crítica às apropriações neoliberais e pós-modernas da teoria vigotskiana. Campinas: Autores Associados, 2000. (Coleção educação contemporânea).

FISCHER, N. B.; LOUSADA, V. L. Risco (verbete). In: STRECK, D.; REDIN, E.; ZITKOSKI, J. J. (Org.). Dicionário Paulo Freire. Belo Horizonte: Autêntica Editora, 2010. p. 363-364.

FREIRE, P. Educação e Mudança. 20. ed. Rio de Janeiro: Paz e Terra, 1979.

. Educação: o sonho possível. 3. ed. In: BRANDÃO, C. R. (Org.). O Educador:Vida e Morte. Rio de Janeiro: Edições Graal, 1983. p. 89-101.

; SHOR, I. Medo e Ousadia: o cotidiano do professor. 3. ed. Rio de Janeiro: Paz e Terra, 1986.

. Pedagogia do Oprimido. 22. ed. Rio de Janeiro: Paz e Terra, 1987. et al. Pedagogía, Diálogo e Conflicto. São Paulo: Cortez, 1988.

. A Educação na Cidade. São Paulo: Cortez, 1991.

. Pedagogia da Esperança: Um reencontro com a Pedagogia do oprimido. Rio de Janeiro: Paz e Terra, 1992. 
. À Sombra desta Mangueira. São Paulo: Olho D’Agua, 1995.

.Pedagogia da autonomia: Saberes necessários à prática educativa. São Paulo: Paz e Terra, 1996.

(1993). Política e Educação: ensaios. 3. ed. São Paulo, Cortez, 1997. (Coleção questões da nossa época; v. 23).

. Pedagogia da Indignação: cartas pedagógicas e outros escritos. São Paulo: Editora UNESP, 2000.

FREITAS, A. L. S. de. Pedagogia da Conscientização - Um legado de Paulo Freire à formação de professores. Porto Alegre: EDIPUCRS, 2001.

. Leituras de Paulo Freire: uma trilogia de referência. Passo Fundo, RS: Méritos, 2014. v.1.

; GHIGGI, G.; PEREIRA; T. I. Paulo Freire em diálogo com outros(as) autores(as). Passo Fundo, RS: Méritos, 2014.

GRILLO, M. C. et al. A gestão da aula universitária na PUCRS. Porto Alegre, RS: EDIPUCRS, 2008.

LEACH, T. "Paulo Freire: Dialogue, Politics and Relevance". International Journal of Lifelong Education, v. 1, n. 3, p. 185-201, 1982.

LUFT, M. H.; FALKEMBACH, E. M. F. (Org.). Freire na agenda da educação: educação ambiental e outros autores. Ijuí, RS: Ed. Unijuí, 2013. 184 p. v. 3. (Coleção educação popular e movimentos sociais).

MEIRIEU, P. "Même pas peur de la peur!". Disponível em: <https://www.meirieu.com/ ARTICLES/La_peur.pdf >. Acesso em: 03 nov. 2016.

MENDONÇA, S.;TORTELLA, J. C. B.; SILVA, A. O. Interesse e a superação do learnification para a prática filosófica. Linhas Críticas, Brasília, v. 19, n. 40, p. 595-608, set./dez. 2013.

MIZUKAMI, Maria da Graça Nicoletti. Ensino: As Abordagens do Processo. São Paulo: LTC, 2012.

MORAES, M. C et al. LabsMóveis: Innovation in the University Classroom through Mobile Devices. In: ROCHA, A. et al. (Org.). Advances in Intelligent Systems and Computing. Switzerland: Springer International Publishing, 2015. p. 1183-1191.

MORAES, M. C. et al. LabTEAR: uma experiência de aplicação dos princípios da mediação pedagógica na aula universitária. LACLO 2011, v. 4, p. 01-06, 2013.

PASSETTI, E. Conversação Libertária com Paulo Freire. São Paulo: Imaginário, 1998.

RANCIÈRE, J. The Ignorant Schoolmaster. Five Lessons in Intellectual Emancipation. Stanford, CA: Stanford University Press, 1991.

SCHUGURENSKY, D. “The Legacy of Paulo Freire: A Critical Review of His Contributions”. Convergence, v. 31, n. 1-2, p. 1-13, 1998. 
SMEYERS, P.; SMITH, R.; STANDISH, P. The Therapy of Education: Philosophy, Happiness and Personal Growth. Basingstoke; New York: Palgrave MacMillan, 2010.

STRECK, D.; REDIN, E.; ZITKOSKI, J. J. (Org.). Dicionário Paulo Freire. 2 ed. Belo Horizonte: Autêntica Editora, 2010.

SUISSA, J. "Untangling the Mother Knot: some thoughts on parents, children and philosophers of education". Ethics and Education, v. 1, n. 1, p. 65-77, 2005.

WITTGENSTEIN, L. Philosophical Investigations. Oxford: Basil Blackwell, 1953.

Alexandre Anselmo Guilherme: Doutor em Filosofia pela Durham University e pós-doutorado pelo Institute of Advanced Studies in Humanity, University of Edinburgh. Atualmente é professor adjunto do PPGEdu da PUCRS, atuando principalmente nos seguintes temas: educação e violência, e educação e diálogo.

E-mail: alexandre.guilherme@pucrs.br

Ana LUCIA SOUZA de Freitas: Doutora em Educação pela PUCRS e pós-doutorado em Educação pela Liverpool Hope University. Atualmente integra o corpo docente do Mestrado Profissional em Gestão Educacional da UNISINOS, atuando na linha de pesquisa: Gestão Escolar e Universitária.

E-mail: 0311anafreitas@gmail.com 